\title{
An EPQ-Based Inventory Model for Deteriorating Items under Stock-Dependent Demand with Immediate Part Payment
}

\author{
P. Majumder, U. K. Bera \\ Department of Mathematics, National Institute of Technology, Agartala, Barjala, Jirania, India \\ Email: pinki.mjmdr@rediffmail.com, bera_uttam@yahoo.co.in
}

Received July 2013

\begin{abstract}
In this paper, an EPQ-based inventory policy for an item is presented with stock-dependent demand during two trade credit periods. In addition, there is a provision for 1) an immediate part payment to the wholesaler, 2) borrowing some money from money lending source for the immediate part payment, 3 ) here supplier or wholesaler offers a trade credit period to his retailer and retailer also offers a trade credit period to his customer. Against the above conjectures inventory model has been formulated with respect to the retailer's point of view for minimizing the total inventory cost. The non-linear optimization method-Generalized Reduced Gradient (GRG) method is used to find the optimal solutions. Lastly Numerical examples are set to illustrate this model. Finally we use LINGO software to solve this model.
\end{abstract}

Keywords: EPQ Model; Immediate Part Payment

\section{Introduction}

Normally, the payment for an order is made by the retailer to the supplier immediately just after the receipt of the consignment. Nowadays, due to the stiff competition in the market to attract more customers, a credit period is offered by the supplier to the retailer. Before the end of the trade credit period, the retailer can sell the goods, accumulate revenue and earn interest. Goyal [1] first explored a single item EOQ model under permissible delay in payments and Chung [2] simplified the search of the optimal solution for the problem explored by Goyal [1]. However, the phenomenon of deterioration was ignored in the above models. Aggarwal and Jaggi [3] extended Goyal's model to the case with deteriorating items. Jamal et al. [4] further generalized the above inventory model to allow for shortages. Sarker et al. [5] developed a model to determine an optimal ordering policy for deteriorating items under inflation, permissible delay in payments and allowable shortage. Chang [6] established an EOQ model for deteriorating items under inflation when the supplier offers a permissible delay to the purchaser if the order quantity is greater than a predetermined quantity. Chung and Huang [7] further extended Goyal's model to the case that the units are replenished at a finite rate under delay in payments. All the above papers under trade credit financing assumed that the market demand was either constant or merely dependent on the retailing price Liao et al. [8] considered an initial-stock-level-dependent demand rate, i.e. the demand rate is influenced by the retailer's order quantity. More recently, Sana and Chaudhuri [9] analyzed a kind of EOQ model with current-stock-dependent demand rate where the supplier gives a retailer both a credit period and a price discount on the purchase of merchandise. Soni and Shah [10] developed the optimal ordering policy for retailer when demand is stock-dependent and when supplier offers two progressive credit periods. But these models with current stock-dependent failed to consider deterioration phenomenon. In the real life, however, deterioration of items is a common phenomenon. On the other hand, the entire above model assumed that the supplier would offer the retailer a delay period but the retailer would not offer the trade credit period to his/her customers. In most business transactions, especially in supply chain, this assumption is unrealistic. Huang assumed that the retailer will also adopt the trade credit policy to his/her customers to promote market competition and developed the retailer's replenishment model that is a two-level trade credit. Min and Zhao [11] introduced an inventory model with stock-dependent demand under two level of trade credit period.

Nowadays for the speedy movement of capital, a wholesaler tries to maximize his/her market through several means. For this, very often some concessions in terms of unit price, credit period etc. are offered to the retailers against immediate part payment. To avail these 
benefits, a retailer is tempted to cash down a part of the payment immediately even making a loan from money lending source which charges interest against this loan. Here an amount, borrowed from the money lending source as a loan with interest, is paid to the wholesaler at the beginning on receipt of goods. In return, the wholesaler/supplier offers a relaxed credit period as permissible delay in payment of rest amount. The concept "immediate part payment" was first introduced by M. Maiti [12]. Guria, Das, Mondal and Maiti ntroduced an inventory policy for an item with inflation induced purchasing price, selling price and demand with immediate part payment.

In this paper, we develop a more general inventory model with delay in payment. Firstly, the demand rate of the items is assumed to be dependent on the retailer's current stock level. Secondly, the items start deteriorating from the moment they are put into inventory. Thirdly not only would the supplier offer a fixed credit period to the retailer, but the retailer also adopts the trade credit policy to his/her customers. Fourthly the supplier must be given an immediate part-payment by the retailer. Lastly these models are illustrated with numerical examples. Finally we use GRG method and LINGO software to solve this model.

\section{Notations and Assumptions}

The following notations and assumptions are used throughout the paper

\section{Notations:}

1) $I(t)=$ Inventory level at time $t$.

2) $k=$ Production rate per year.

3) $r=$ The unit raw material cost.

4) $C_{1}=$ The unit selling cost.

5) $p=$ The unit production cost. Where $\mathrm{p}=\mathrm{r}+l / k+$ wk $+\mathrm{e} \sqrt{k}$

6) $c_{2}=$ The ordering cost per order.

7) $C_{3}^{2}=$ Setup cost.

8) $1=$ Cost due to labour.

9) $w=$ Cost due to wear and tear.

10) $\mathrm{e}=$ Environmental protection cost.

11) $\mathrm{h}=$ The inventory holding cost per year excluding interest charges.

12) $\mathrm{A}=$ Immediate part payment.

13) $\mathrm{M}=$ Retailer's trade credit period

14) $\mathrm{N}=$ Customer's trade credit period offered by the supplier.

15) $I_{c}=$ Interest payable per $\$$ per year by the retailer to the supplier.

16) $I_{e}=$ Interest earned per $\$$ per year by the retailer to the retailer.

17) $I_{b}=$ Rate of interest per unit to be paid by the retailer to money lender against immediate part payment A.
18) $T=$ Cycle time in years.

19) $T^{*}=$ Optimal cycle time.

20) $Z(T)=$ Total inventory cost per time period.

\section{Assumptions:}

1) The demand rate $R(t)$ is a known function of retailer's instantaneous stock level $\mathrm{I}(\mathrm{t})$, which is given by $\mathrm{R}(\mathrm{t})$ $=\mathrm{D}+\alpha \mathrm{I}(\mathrm{t})$, where $\mathrm{D}$ and $\alpha$ are positive constants.

2) Shortages are not allowed to occur.

3) The time horizon of the inventory system is infinite.

4) The lead time is negligible.

5) The fixed credit period offered by the supplier to the retailer is no less than the credit period permitted by the retailer to his/her customers i.e. $M \geq \mathrm{N}$.

6) When $T \geq M$, the account is settled at $t=M$ and the retailer would pay for the interest charges on items in stock with rate $\mathrm{I}_{\mathrm{c}}$ over the interval $[\mathrm{M}, \mathrm{T}]$. When $\mathrm{T} \leq$ $\mathrm{M}$, the account is also settled at $\mathrm{t}=\mathrm{M}$ and the retailer does not need to pay any interest charge of items in stock during the whole cycle.

\section{Mathematical Formulation of the Model}

A constant production starts at $\mathrm{t}=0$ and continues up to $t=t_{1}$ where the inventory level reaches maximum level. Production then stops at $t=t_{1}$ and the inventory gradually depletes to zero at the end of the production cycle $t=$ $\mathrm{T}$ due to deterioration and consumption. Therefore, during the time interval $\left(0, t_{1}\right)$, the system is subject to the effect of production, demand and deterioration.

Then the change in the inventory level can be described by the following differential equation:

$$
\frac{d q_{1}(t)}{d t}+\theta q_{1}(t)=k-D-\alpha q_{1}(t), 0 \leq t \leq t_{1}
$$

With the initial condition $q_{1}(0)=0$

On the other hand, in the interval $\left(t_{1}, T\right)$, the system is effected by the combined effect of demand and deterioration.

Hence, the change in the inventory level is governed by the following differential equation:

$$
\frac{d q_{2}(t)}{d t}+\theta q_{2}(t)=-D-\alpha q_{2}(t), t_{1} \leq t \leq T
$$

With the ending condition $q_{2}(T)=0$

The solution of the differential Equations (1) and (3) are respectively represented by

$$
\begin{gathered}
q_{1}(t)=\frac{(k-D)}{(\alpha+\theta)}\left(1-e^{-(\alpha+\theta) t}\right) ; 0 \leq t \leq t_{1} \\
q_{2}(t)=\frac{D}{(\alpha+\theta)}\left(e^{(\alpha+\theta)(T-t)}-1\right) ; t_{1} \leq t \leq T
\end{gathered}
$$

In addition, using the boundary condition $q_{1}\left(t_{1}\right)=q_{2}\left(t_{1}\right)$, we obtain the following equations: 


$$
\begin{gathered}
\frac{(k-D)}{(\alpha+\theta)}\left(1-e^{-(\alpha+\theta) t_{1}}\right)=\frac{D}{(\alpha+\theta)}\left(e^{(\alpha+\theta)\left(T-t_{1}\right)}-1\right) \\
\text { and } t_{1}=\frac{1}{(\alpha+\theta)} \ln \left[1+\frac{D}{k}\left(e^{(\alpha+\theta) T}-1\right)\right]
\end{gathered}
$$

The annual total relevant cost

1) Annual ordering cost $=c_{2} / T$

2) Annual stock holding cost

$$
\begin{aligned}
& =\frac{h}{T}\left[\int_{0}^{t_{1}} q_{1}(t) d(t)+\int_{t_{1}}^{T} q_{2}(t) d(t)\right] \\
& =\frac{h}{(\alpha+\theta) T}\left(\mathrm{k} t_{1}-\mathrm{DT}\right)
\end{aligned}
$$

3) Annual cost due to deteriorated units

$$
=\frac{r}{(\alpha+\theta) T}\left(\mathrm{k} t_{1}-\mathrm{DT}\right)
$$

4) Annual Production cost $=\frac{p k t_{1}}{T}$

5) Annual Set up cost $=\frac{C_{3}}{T}$

Depending upon $M, N$ and $T$ three cases arise:

Case-1: $\mathrm{N} \leq M \leq T$, Case $2:-\mathrm{N} \leq T \leq M$, Case 3:$\mathrm{T} \leq N \leq M$

According to given assumption, there are three cases to occur in interest charged for the items kept in stock per year.

Case-1. $\mathrm{M} \leq T$

Annual interest payable

$$
\begin{aligned}
& =\left[\frac{r I_{c}}{T} \int_{M}^{T} q_{2}(t) d t+A I_{b}\right] \\
& =\frac{r I_{c}}{T} \cdot \frac{D}{(\alpha+\theta)^{2}}\left[e^{(\alpha+\theta)(T-M)}-(\alpha+\theta)(T-M)-1\right]+A I_{b}
\end{aligned}
$$

Case-2. $\mathrm{N} \leq T \leq M$

In this case total interest payable $=\mathrm{A} I_{b}$

Case-3. $\mathrm{T} \leq N \leq M$

In this case total interest payable $=\mathrm{A} I_{b}$

(v) According to given assumption, three cases will occur in interest earned per year.

Case-1. $\mathrm{N} \leq \mathrm{M} \leq T$

The annual interest earned by the retailer

$$
\begin{aligned}
& =\frac{I_{e}}{T}\left\{c _ { 1 } \left[\frac{\theta D\left(M^{2}-N^{2}\right)}{2(\alpha+\theta)}+\frac{\alpha D(M-N)}{(\alpha+\theta)^{2}} e^{(\alpha+\theta) T}+\right.\right. \\
& \left.\left.\frac{\alpha D}{(\alpha+\theta)^{3}} e^{(\alpha+\theta) T}\left(e^{-(\alpha+\theta) M}-e^{-(\alpha+\theta) N}\right)\right]-A\right\}
\end{aligned}
$$

Case -2 . $\mathrm{N} \leq T \leq M$

The annual interest earned by the retailer

$$
\begin{aligned}
& =\frac{\mathrm{I}_{\mathrm{e}}}{\mathrm{T}}\left\{\mathrm { c } _ { 1 } \left[\frac{\theta \mathrm{D}\left(\mathrm{T}^{2}-\mathrm{N}^{2}\right)}{2(\alpha+\theta)}+\frac{\alpha \mathrm{D}(\mathrm{T}-\mathrm{N})}{(\alpha+\theta)^{2}} \mathrm{e}^{(\alpha+\theta) \mathrm{T}}\right.\right. \\
& -\frac{\alpha \mathrm{D}}{(\alpha+\theta)^{3}}\left(\mathrm{e}^{(\alpha+\theta)(\mathrm{T}-\mathrm{N})}-1\right) \\
& \left.\left.+\left(\frac{\theta \mathrm{DT}}{(\alpha+\theta)}+\frac{\alpha \mathrm{D}}{(\alpha+\theta)^{2}}\left(\mathrm{e}^{(\alpha+\theta) \mathrm{T}}-1\right)\right)(\mathrm{M}-\mathrm{T})\right]-\mathrm{A}\right\}
\end{aligned}
$$

Case-3. $T \leq N \leq M$

The annual interest earned by the retailer

$$
=\frac{I_{e}}{T}\left\{C_{1}\left[\frac{\theta D T}{(\alpha+\theta)}+\frac{\alpha D}{(\alpha+\theta)^{2}}\left(e^{(\alpha+\theta) \mathrm{T}}-1\right)\right](M-N)-A\right\}
$$

The annual total cost incurred by the retailer

$Z(T)=$ Ordering cost + holding cost + set up cost + de terioration cost + production cost + interest payable interest earned

$$
\mathrm{Z}(\mathrm{T})=\left\{\begin{array}{c}
Z_{1}(T), \text { if } T \geq M \\
Z_{2}(T), \text { if } N \leq T \leq M \\
Z_{2}(T), \text { if } o<T \leq N
\end{array}\right.
$$

where

$$
\begin{aligned}
& \mathbf{Z}_{1}(\mathbf{T})=\frac{c_{2}}{T}+\frac{h}{(\alpha+\theta) T}(k-D T) \\
& +\frac{r}{(\alpha+\theta) T}(k-D T) \div \frac{p k t_{1}}{T}+\frac{c_{3}}{T} \\
& \frac{r I_{c}}{T} \cdot \frac{D}{(\alpha+\theta)^{2}}\left[e^{(\alpha+\theta)(T-M)}-(\alpha+\theta)(T\right. \\
& -M)-1]+A I_{b}-\frac{I_{e}}{T}\left\{c _ { 1 } \left[\frac{\theta D\left(M^{2}-N^{2}\right)}{2(\alpha+\theta)}\right.\right. \\
& +\frac{\alpha D(M-N)}{(\alpha+\theta)^{2}} e^{(\alpha+\theta) T} \\
& \left.\left.+\frac{\alpha D}{(\alpha+\theta)^{3}} e^{(\alpha+\theta) T}\left(e^{-(\alpha+\theta) M}-e^{-(\alpha+\theta) N}\right)\right]-A\right\} \\
& \mathbf{Z}_{2}(\mathbf{T})=\frac{c_{2}}{T}+\frac{h}{(\alpha+\theta) T}\left(k t_{1}-D T\right) \\
& +\frac{r}{(\alpha+\theta) T}\left(k t_{1}-D T\right)+\frac{p k t_{1}}{T}+\frac{c_{3}}{T} \\
& +A I_{b}-\frac{\mathrm{I}_{\mathrm{e}}}{\mathrm{T}}\left\{\mathrm { c } _ { 1 } \left[\frac{\theta \mathrm{D}\left(\mathrm{T}^{2}-\mathrm{N}^{2}\right)}{2(\alpha+\theta)}+\frac{\alpha \mathrm{D}(\mathrm{T}-\mathrm{N})}{(\alpha+\theta)^{2}} \mathrm{e}^{(\alpha+\theta) \mathrm{T}}\right.\right. \\
& -\frac{\alpha \mathrm{D}}{(\alpha+\theta)^{3}}\left(\mathrm{e}^{(\alpha+\theta)(\mathrm{T}-\mathrm{N})}-1\right)+\left(\frac{\theta \mathrm{DT}}{(\alpha+\theta)}+\frac{\alpha \mathrm{D}}{(\alpha+\theta)^{2}}\right. \\
& \left.\left.\left.\left.\left(\mathrm{e}^{(\alpha+\theta) \mathrm{T}}-1\right)\right)(\mathrm{M}-\mathrm{T})\right]\right]-\mathrm{A}\right\}
\end{aligned}
$$




$$
\begin{gathered}
\mathbf{Z}_{3}(\mathbf{T})=\frac{c_{2}}{T}+\frac{h}{(\alpha+\theta) T}\left(\mathrm{k} t_{1}-\mathrm{DT}\right)+\frac{r}{(\alpha+\theta) T}\left(\mathrm{k} t_{1}-\mathrm{DT}\right) \\
+\frac{p k t_{1}}{T}+\frac{c_{3}}{T}+A I_{b}-\frac{I_{e}}{T}\left\{c _ { 1 } \left[\frac{\theta D T}{(\alpha+\theta)}+\frac{\alpha D}{(\alpha+\theta)^{2}}\right.\right. \\
\left.\left.\left(e^{(\alpha+\theta) \mathrm{T}}-1\right)\right](M-N)-A\right\}
\end{gathered}
$$

Since $Z_{1}(M)=Z_{2}(M)$ and $Z_{2}(N)=Z_{3}(N)$ Therefore $Z(T)$ is continuous and well defined.

All $Z_{1}(T), Z_{2}(T), Z_{3}(T)$ are defined on $T>0$.

Equations (9)-(11) yield

$$
\begin{aligned}
& Z_{1}^{\prime}(t)=-\frac{c_{2}}{T^{2}}-\frac{h}{(\alpha+\theta) T^{2}}\left(k t_{1}-D T\right) \\
& +\frac{h}{(\alpha+\theta) T}\left(k \frac{d t_{1}}{d T}-D\right)-\frac{r}{(\alpha+\theta) T^{2}}\left(k t_{1}-D T\right) \\
& +\frac{r}{(\alpha+\theta) T}\left(k \frac{d t_{1}}{d T}-D\right)+\frac{T p k \frac{d t_{1}}{d T}-p k t_{1}}{T^{2}}-\frac{c_{3}}{T^{2}} \\
& -\frac{r I_{c}}{T^{2}} \cdot \frac{D}{(\alpha+\theta)^{2}}\left[e^{(\alpha+\theta)(T-M)}-(\alpha+\theta)(T-M)-1\right] \\
& +\frac{r I_{c}}{T} \cdot \frac{D}{(\alpha+\theta)^{2}}\left[(\alpha+\theta) e^{(\alpha+\theta)(T-M)}-(\alpha+\theta)\right] \\
& +\frac{I_{e}}{T^{2}}\left\{c _ { 1 } \left[\frac{\theta D\left(M^{2}-N^{2}\right)}{2(\alpha+\theta)}+\frac{\alpha D(M-N)}{(\alpha+\theta)^{2}} e^{(\alpha+\theta) T}\right.\right. \\
& \left.\left.+\frac{\alpha D}{(\alpha+\theta)^{3}} e^{(\alpha+\theta) T}\left(e^{-(\alpha+\theta) M}-e^{-(\alpha+\theta) N}\right)\right]-A\right\} \\
& -\frac{I_{e}}{T}\left\{c _ { 1 } \left[\frac{\alpha D(M-N)}{(\alpha+\theta)} e^{(\alpha+\theta) T}+\frac{\alpha D}{(\alpha+\theta)^{2}} e^{(\alpha+\theta) T}\right.\right. \\
& \left.\left(\left(e^{-(\alpha+\theta) M}-e^{-(\alpha+\theta) N}\right)\right]\right\} \\
& Z_{2}^{\prime}(t)=-\frac{c_{2}}{T^{2}}-\frac{h}{(\alpha+\theta) T^{2}}\left(k t_{1}-D T\right)+\frac{h}{(\alpha+\theta) T} \\
& \left(k \frac{d t_{1}}{d T}-D\right)-\frac{r}{(\alpha+\theta) T^{2}}\left(k t_{1}-D T\right) \\
& +\frac{r}{(\alpha+\theta) T}\left(k \frac{d t_{1}}{d T}-D\right)+\frac{T p k \frac{d t_{1}}{d T}-p k t_{1}}{T^{2}}-\frac{c_{3}}{T^{2}} \\
& +\frac{I_{e}}{T^{2}}\left\{C _ { 1 } \left[\frac{\theta D\left(T^{2}-N^{2}\right)}{2(\alpha+\theta)}-\frac{\alpha D}{(\alpha+\theta)^{3}}\left(e^{(\alpha+\theta)(T-N)}-1\right)\right.\right. \\
& +\frac{\alpha D}{(\alpha+\theta)^{2}}(T-N) e^{(\alpha+\theta) T} \\
& +\left(\frac{\theta D T}{(\alpha+\theta)}+\frac{\alpha D}{(\alpha+\theta)^{2}}\left(e^{(\alpha+\theta) T}-1\right)\right)
\end{aligned}
$$

$$
\begin{aligned}
& +\frac{I_{e}}{T^{2}}\left\{c_{1}\left[\frac{\theta D T}{(\alpha+\theta)}+\frac{\alpha D}{(\alpha+\theta)^{2}}\left(e^{(\alpha+\theta) T}-1\right)\right]\right. \\
& (M-N)-A\}-\frac{I_{e}}{T}\left\{c _ { 1 } \left[\frac{\theta D}{(\alpha+\theta)}+\frac{\alpha D}{(\alpha+\theta)^{2}}\right.\right. \\
& \left.\left.\left((\alpha+\theta) e^{(\alpha+\theta) T}\right)\right](M-N)\right\} \\
& \quad \text { Now } Z_{1}^{\prime}(t)=0 \\
& \Rightarrow-(\alpha+\theta)^{3} c_{2}+(h+r)(\alpha+\theta)^{2}\left(k T \frac{d t_{1}}{d T}-k t_{1}\right) \\
& \quad+(\alpha+\theta)^{3}\left(T p k \frac{d t_{1}}{d T}-p k t_{1}\right)-(\alpha+\theta)^{3} c_{3} \\
& \quad-r I_{c} D(\alpha+\theta)\left[e^{(\alpha+\theta)(T-M)}-(\alpha+\theta)(T-M)-1\right] \\
& \quad+r I_{c} D(\alpha+\theta) T\left[(\alpha+\theta) e^{(\alpha+\theta)(T-M)}-(\alpha+\theta)\right] \\
& +I_{e}\left\{c _ { 1 } \left[\frac{\theta D}{2}(\alpha+\theta)^{2}\left(M^{2}-N^{2}\right)+\alpha D(M-N)\right.\right. \\
& \left.\left.(\alpha+\theta) e^{(\alpha+\theta) T}+\alpha D e^{(\alpha+\theta) T}\left(e^{-(\alpha+\theta) M}-e^{-(\alpha+\theta) N}\right)\right]-A\right\}=0 \\
& -I_{e} T\left\{c _ { 1 } \left[\alpha D(M-N)(\alpha+\theta)^{2} e^{(\alpha+\theta) T}\right.\right. \\
& \left.\left.+\alpha D(\alpha+\theta) e^{(\alpha+\theta) T}\left(e^{-(\alpha+\theta) M}-e^{-(\alpha+\theta) N}\right)\right]\right\}
\end{aligned}
$$

The objective of this paper is to find an optimal cycle time to minimize the annual total relevant cost for the retailer. For this the optimal cycle time $T_{1}^{*}$ is obtained by setting the Equation (12) equal to zero; is the root of the following equation

$$
\begin{aligned}
& -(\alpha+\theta)^{3} c_{2}+(h+r)(\alpha+\theta)^{2}\left(k T \frac{d t_{1}}{d T}-k t_{1}\right) \\
& +(\alpha+\theta)^{3}\left(T p k \frac{d t_{1}}{d T}-p k t_{1}\right)-(\alpha+\theta)^{3} c_{3}
\end{aligned}
$$




$$
\begin{aligned}
& \quad-I_{c} D(\alpha+\theta)\left[e^{(\alpha+\theta)(T-M)}-(\alpha+\theta)(T-M)-1\right] \\
& \quad+r I_{c} D(\alpha+\theta) T\left[(\alpha+\theta) e^{(\alpha+\theta)(T-M)}-(\alpha+\theta)\right] \\
& +I_{e}\left\{C _ { 1 } \left[\frac{\theta D}{2}(\alpha+\theta)^{2}\left(M^{2}-N^{2}\right)+\alpha D(M-N)\right.\right. \\
& \left.\left.(\alpha+\theta) e^{(\alpha+\theta) T}+\alpha D e^{(\alpha+\theta) T}\left(e^{-(\alpha+\theta) M}-e^{-(\alpha+\theta) N}\right)\right]-A\right\} \\
& -I_{e} T\left\{c _ { 1 } \left[\alpha D(M-N)(\alpha+\theta)^{2} e^{(\alpha+\theta) T}\right.\right. \\
& \left.+\alpha D(\alpha+\theta) e^{(\alpha+\theta) T}\left(e^{-(\alpha+\theta) M}-e^{-(\alpha+\theta) N}\right)\right] \\
& =0
\end{aligned}
$$$$
\text { Equation(15)is the optimality condition of (9) }
$$$$
\text { Now } Z_{2}^{\prime}(\mathrm{t})=0
$$$$
\Rightarrow-(\alpha+\theta)^{3} c_{2}+(h+r)(\alpha+\theta)^{2}\left(k T \frac{d t_{1}}{d T}-k t_{1}\right)
$$$$
+(\alpha+\theta)^{3}\left(T p k \frac{d t_{1}}{d T}-p k t_{1}\right)-(\alpha+\theta)^{3} c_{3}
$$$$
+I_{e}\left\{c _ { 1 } \left[\frac{\theta D}{2}(\alpha+\theta)^{2}\left(T^{2}-N^{2}\right)+\alpha D(T-N)\right.\right.
$$$$
(\alpha+\theta) e^{(\alpha+\theta) T}-\alpha D\left(e^{(\alpha+\theta)(T-N)}-1\right)
$$$$
\left.+\left(\theta D T(\alpha+\theta)^{2}+\alpha D(\alpha+\theta)\left(e^{(\alpha+\theta) T}-1\right)\right)(M-T)\right]
$$$$
-A\}-I_{e} T\left\{c _ { 1 } \left[D \theta(\alpha+\theta)^{2} T-\alpha D(\alpha+\theta) e^{(\alpha+\theta)(T-N)}\right.\right.
$$$$
+\alpha D(\alpha+\theta)^{2}(T-N) e^{(\alpha+\theta) T}+\alpha D(\alpha+\theta) e^{(\alpha+\theta) T}
$$$$
+\left(\theta D(\alpha+\theta)^{2}+\alpha D(\alpha+\theta)^{2} e^{(\alpha+\theta) T}\right)(M-T)
$$$$
\left.\left.-\left((\alpha+\theta)^{2} \theta D T+\alpha D(\alpha+\theta)\left(e^{(\alpha+\theta) T}-1\right)\right)\right]\right\}
$$$$
=0
$$

Equation(16) is the optimality condition of (10) Again $Z_{3}^{\prime}(\mathrm{t})=0$

$$
\begin{aligned}
& \Rightarrow-(\alpha+\theta)^{3} c_{2}+(h+r)(\alpha+\theta)^{2}\left(k T \frac{d t_{1}}{d T}-k t_{1}\right) \\
& +(\alpha+\theta)^{3}\left(T p k \frac{d t_{1}}{d T}-p k t_{1}\right)-(\alpha+\theta)^{3} c_{3} \\
& +I_{e}\left\{c_{1}\left[\theta(\alpha+\theta)^{2} D T+\alpha D(\alpha+\theta)\left(e^{(\alpha+\theta) T}-1\right)\right]\right. \\
& (M-N)-A\} \\
& -I_{e} T\left\{c_{1}\left[\theta D(\alpha+\theta)^{2}+\alpha D(\alpha+\theta)^{2} e^{(\alpha+\theta) T}\right]\right. \\
& (M-N)\}=0
\end{aligned}
$$

Equation (17) is the optimality condition of (11)

\section{Numerical Examples}

To illustrate the results of the proposed model we solve the following numerical examples
Example 1. When $c_{1}=R s 150 /$ unit, $c_{2}=R s 100 /$ order $, c_{3}=R s 50, \mathrm{M}=0.5$ year, $\mathrm{N}=0.01$ year, $\mathrm{D}=1500$ units per year , $\mathrm{k}=2000$ units/year, $\mathrm{A}=$ Rs $700, \mathrm{~h}=$ Rs 15/unit,

$\mathrm{r}=$ Rs 4/unit, $1=$ Rs200, $\mathrm{w}=$ Rs 0.0005 , e $=$ Rs 0.1, $I_{e}=0.12, \quad I_{c}=0.17, \quad I_{b}=0.15, \quad \alpha=0.2, \theta=0.2$ then the optimal value of $\mathrm{T}$ is $T_{1}^{*}=5.231635$ and $\mathrm{Z}_{1}\left(T_{1}^{*}\right)=30310.78$

Example 2. When $c_{1}=R s 150 /$ unit,

$c_{2}=R s 100 /$ order $, c_{3}=R s 50, \mathrm{M}=2.5$ year, $\mathrm{N}=0.01$ year, $\mathrm{D}=1000$ units per year, $\mathrm{k}=2500$ units/year, $\mathrm{A}=$ Rs 2000 , h = Rs 10/unit,

$\mathrm{r}=$ Rs 4/unit, $1=$ Rs200, $\mathrm{w}=\mathrm{Rs} 0.05, \mathrm{e}=\mathrm{Rs} 0.1$, $I_{e}=0.12, I_{c}=0.17, I_{b}=0.15, \alpha=0.1, \theta=0.1$ then the optimal value of $T$ is $T_{2}^{*}=1.068099$ and

$\mathrm{Z}_{2}\left(T_{2}^{*}\right)=165639.8$

Example 3. When

$c_{1}=$ Rs136/ unit, $c_{2}=$ Rs100/ order,$c_{3}=$ Rs30 , M=2.1 year, $\mathrm{N}=1.07$ year, $\mathrm{D}=2000$ units per year, $\mathrm{k}=2500$ units/year, $\mathrm{A}=\mathrm{Rs} 2800, \mathrm{~h}=\mathrm{Rs} 10 /$ unit, $\mathrm{r}=\mathrm{Rs} 4 /$ unit, 1 $=\mathrm{Rs} 100, \mathrm{~W}=\mathrm{Rs} 0.05, \mathrm{e}=\mathrm{Rs} 0.1, I_{e}=0.15$, $I_{c}=0.20, I_{b}=0.12, \alpha=0.1, \theta=0.1$ then the optimal value of T is $T_{3}^{*}=0.9165449$ and

$\mathrm{Z}_{3}\left(T_{3}^{*}\right)=79741.83$

\section{Conclusions}

In this paper, we develop an EPQ model for deteriorating items under permissible delay in payments. The primary difference of this paper as compared to previous studies is that we introduced a generalized inventory model by relaxing the traditional EOQ model in the following seven ways: 1) the demand of the items is dependent on the retailer's current stock level, 2) the retailer's selling price per unit is higher than its purchase unit cost, 3) many items deteriorate continuously such as fruits and vegetables, 4) the supplier not only would offer a fixed credit period to the retailer, but the retailer also adopts the trade credit policy to promote market competition, 5) supplier must be given an immediate part payment by the retailer after receipt of goods, 6) minimizing inventory cost is used as the objective to find the optimal replenishment policy. Three numerical examples are set to illustrate this model. For the first example, $T_{1}^{*}$ is the optimal value of $\mathrm{T}$, for second and third, the optimal value of $T$ is $T_{2}^{*}$ and $T_{3}^{*}$ respectively. This presented model can be further extended to some more practical situations, such as we could allow for shortages. Also quantity discounts, time value of money and inflation etc. may be added in this paper.

\section{REFERENCES}

[1] S. K. Goyal, "Economic Order Quantity under Conditions of Permissible Delay in Payments," The Journal of the 
Operational Research Society, Vol. 36, No. 4, 1985, pp. 335-338.

[2] K. J. Chung, "A Theorem on the Determination of Economic Order Quantity under Conditions of Permissible Delay in Payments," Computers \& Operations Research, Vol. 25, No. 1, 1998, pp. 49-52.

[3] S. P. Aggarwal and C. K. Jaggi, "Ordering Policies of Deteriorating Items under Permissible Delay in Payments," The Journal of the Operational Research Society, Vol. 46, No. 5, 1995, pp. 658-662.

[4] A. M. M. Jamal, B. R. Sarker and S. Wang, "An Ordering Policy for Deteriorating Items with Allowable Shortages and Permissible Delay in Payment," The Journal of the Operational Research Society, Vol. 48, 1997, pp. 826833.

[5] B. R. Sarker, A. M. M. Jamal and S. Wang, "Supply Chain Model for Perishable Products under Inflation and Permissible Delay in Payment," Computers \& Operations Research, Vol. 27, No. 1, 2000, pp. 59-75. http://dx.doi.org/10.1016/S0305-0548(99)00008-8

[6] C. T. Chang, "An EOQ Model with Deteriorating Items under Inflation When Supplier Credits Linked to Order Quantity," International Journal of Production Economics, Vol. 88, No. 3, 2004, pp. 307-316. http://dx.doi.org/10.1016/S0925-5273(03)00192-0

[7] K. J. Chung and Y. F. Huang, "The Optimal Cycle Time for EPQ Inventory Model under Permissible Delay in Payments," International Journal of Production Eco- nomics, Vol. 84, No. 3, 2003, pp. 307-318. http://dx.doi.org/10.1016/S0925-5273(02)00465-6

[8] H. C. Liao, C. H. Tsai and C. T. Su, "An Inventory Model with Deteriorating Items under Inflation When a Delay in Payment Is Permissible," International Journal of Production Economics, Vol. 63, No. 2, 2000, pp. 207-214. http://dx.doi.org/10.1016/S0925-5273(99)00015-8

[9] S. S. Sana and K. S. Chaudhuri, "A Deterministic EOQ Model with Delays in Payments and Price-Discount Offers," European Journal of Operational Research, Vol. 184, No. 2, 2008, pp. 509-533. http://dx.doi.org/10.1016/j.ejor.2006.11.023

[10] H. Soni and N. H. Shah, "Optimal Ordering Policy for Stock-Dependent Demand under Progressive Payment Scheme," European Journal of Operational Research, Vol. 184, No. 1, 2008, pp. 91-100. http://dx.doi.org/10.1016/j.ejor.2006.10.048

[11] J. Min, Y.-W. Zhou and J. Zhao, “An Inventory Model for Deteriorating Items under Stock-Dependent Demand and Two-Level Trade Credit," Applied Mathematical Modelling, Vol. 34, No. 11, 2010, pp. 3273-3285. http://dx.doi.org/10.1016/j.apm.2010.02.019

[12] A. Guria, B. Das, S. Mondal and M. Maiti, "Inventory Policy for an Item with Inflation Induced Purchasing Price, Selling Price and Demand with Immediate Part Payment," Applied Mathematical Modelling, Vol. 37, No. 1-2, 2013, pp. 240-257. 